\title{
Outstanding Reviewers and Associate Editors for 2010
}

Approximately a year ago, in this forum, I described our journal's efforts to alleviate the backlog of accepted papers and to streamline our editorial process. In other places, I described the progress that has been taking place in terms of the quality of submissions as well as the number of manuscripts. For example, we have experienced a $30 \%$ increase in submissions since the Davis office assumed the editorial role. We have also expedited the editorial process, such that, for example, manuscripts undergo the editorial process in about 3 weeks. Though this is a work in progress, all of us, members of the Annals of Biomedical Engineering team, should pause for a second and acknowledge the good results. We should also ponder who has been instrumental in enhancing this process. Undoubtedly, the members of our scientific communities in Biomedical Engineering and Bioengineering are submitting strong studies to the journal and we thank them for that. Of course, central to this effort are also the reviewers and associate editors who implement and oversee the peer-review process in an indefatigable manner. Let us also remember that they do this on a volunteer basis.

The objective of this note is to thank all our reviewers and editors for their hard work in 2010. Reviewers completed a total of 2061 reviews, with a turnaround time of only 14 days from the date of invitation. There is no doubt in my mind that these people do this because of their love for our profession. They do this because it is everyone's desire to elevate our Society's flagship journal to the very top of scientific publications. Although all of our reviewers and editors contributed to our excellence last year, we would like to honor those with particularly noteworthy accomplishments. Each of them received a special certificate at the end of the year. Here is the list:

\section{REVIEWERS}

Top Reviewer

Baoshun Ma, University of Vermont, Burlington, VT, USA

$$
\text { Reviewer Excellence }
$$

Estefanía Peña, University of Zaragoza, Zaragoza, Spain

Yong He, University of Florida, Gainesville, FL, USA Yang Sun, University of California, Davis, CA, USA Niranjan Chakravarthy, Corventis, Inc., Minneapolis, MN, USA

\section{ASSOCIATE EDITORS}

\section{Exceptional Past and Current Contributions}

Peter McHugh, National University of Ireland, Galway, Ireland

Sean Kohles, Kohles Bioengineering, Portland, OR, USA

\section{Outstanding Special Issue}

Michael Detamore, University of Kansas, Lawrence, KS, USA

\section{Editorial Excellence}

Jane Grande-Allen, Rice University, Houston, TX, USA

Eric Darling, Brown University, Providence, RI, USA

On behalf of the Annals of Biomedical Engineering, my gratitude goes to these individuals and to all of our readers, authors, reviewers, and editors for your continued support.

K.A. Athanasiou

Davis, CA 